\title{
Association of Blood Pressure and Hypertension with Alcohol Consumption in HIV-Infected White and Nonwhite Patients
}

\author{
Maria Leticia R. Ikeda, ${ }^{1,2}$ Nêmora T. Barcellos, ${ }^{3,4}$ Paulo R. Alencastro, ${ }^{2,4}$ \\ Fernando H. Wolff, ${ }^{3,4}$ Ajácio B. M. Brandão, ${ }^{3}$ Flávio D. Fuchs, ${ }^{1,4}$ and Sandra C. Fuchs ${ }^{1,3,4}$ \\ ${ }^{1}$ Postgraduate Program in Cardiology, School of Medicine, Universidade Federal do Rio Grande do Sul, R. Ramiro Barcelos 2600, \\ 90035-003 Porto Alegre, RS, Brazil \\ ${ }^{2}$ Hospital Sanatório Partenon, Health State Department of Rio Grande do Sul 3722, Avenida Bento Gonçalves, \\ 90650-001 Porto Alegre, RS, Brazil \\ ${ }^{3}$ Postgraduate Program in Epidemiology, School of Medicine, Universidade Federal do Rio Grande do Sul, R. Ramiro Barcelos 2600, \\ 90035-003 Porto Alegre, RS, Brazil \\ ${ }^{4}$ National Institute for Health Technology Assessment (IATS/CNPq), Clinical Research Center, Hospital de Clinicas de Porto Alegre, \\ R. Ramiro Barcelos 2350, 90035-003 Porto Alegre, RS, Brazil
}

Correspondence should be addressed to Sandra C. Fuchs; scfuchs@terra.com.br

Received 11 July 2013; Accepted 20 August 2013

Academic Editors: H. A. Beydoun, G.-X. Jiang, and L. Kuller

Copyright (C) 2013 Maria Leticia R. Ikeda et al. This is an open access article distributed under the Creative Commons Attribution License, which permits unrestricted use, distribution, and reproduction in any medium, provided the original work is properly cited.

\begin{abstract}
Introduction. Although alcohol abuse is associated with hypertension in whites and nonwhites, it has been scarcely investigated in HIV-infected patients. Objective. To investigate whether the association of alcohol abuse with hypertension is influenced by skin color in HIV-infected individuals. Methods. Cross-sectional study in HIV-infected individuals aged 18 years or older. Demographic characteristics, lifestyle, and HIV infection were investigated. Alcohol abuse was defined as $\geq 15$ (women) and $\geq 30 \mathrm{~g} /$ alcohol/day (men), and binge drinking by the intake of $\geq 5$ drinks on a single occasion. Hypertension was defined by blood pressure $\geq 140 / 90 \mathrm{mmHg}$ or use of blood pressure-lowering agents. Results. We studied 1,240 individuals, with $39.1 \pm 10$ years, $51 \%$ males and 57\% whites. Age and body mass index were associated with blood pressure, and there was an independent association of alcohol abuse with hypertension in whites $(\mathrm{RR}=1.9,95 \% \mathrm{CI} 1.1-3.3)$ and nonwhites $(\mathrm{RR}=2.4,95 \% \mathrm{CI} 1.4$ to 4.0$)$. Among nonwhite individuals who were alcohol abusers, systolic $(9.3 \pm 3.2 ; P=0.001)$ and diastolic blood pressures $(6.4 \pm 2.1 ; P=0.008)$ were higher than in nonabusers. Conclusion. Alcohol abuse is a risk factor for hypertension in white and nonwhite HIV-infected individuals. The association of ethanol consumption with blood pressure is not explained by AIDS-related conditions.
\end{abstract}

\section{Introduction}

Hypertension is a major cardiovascular risk factor worldwide. Projections are that, by the year of $2025,75.0 \%$ (or 1.17 billion people) of the people with hypertension in the world will be living in emerging nations [1]. In Brazil, about $29 \%$ of the Brazilian population has hypertension [2]. Alcohol abuse is associated with elevated blood pressure [3], regardless of other risk factors [4-6]. Different studies have shown prevalence rates of hypertension attributed to alcohol consumption ranging from 5 to $30 \%$ [7].

Risk factors for cardiovascular diseases, including hypertension and dyslipidemia, are determinants of reduced life expectancy in HIV-infected patients [8]. Hypertension prevalence in HIV-infected individuals ranges from 5.9 to $56.4 \%$ [9-12] and has been associated with alcohol abuse and other factors related to HIV infection $[9,10,13]$. In these individuals, the prevalence of alcohol abuse ranges from $8 \%[14,15]$ to $50 \%$ [16-18], exceeding the rates in general populations of the United States [19], Europe [20], and Brazil [21], where the prevalence is between 2 and $41 \%$ in men and 0.1 and $21 \%$ in women [20].

The relationship between alcohol consumption and hypertension may be influenced by some characteristics, such as skin color $[3,22]$. Skin color has been identified as a marker of lifestyle $[3,23,24]$ and, in some countries, it may also be 
characterized as the socioeconomic status of the individuals [4]. In Brazil, the HIV-infected population tends to be more homogeneous in terms of socioeconomic status, affecting the less privileged ones. High blood pressure has been associated with low socioeconomic status [4] and skin color may also be a risk factor. Therefore, the objective of the present study was to investigate if the association between alcohol abuse, blood pressure, and hypertension in HIV-infected patients is influenced by skin color.

\section{Materials and Methods}

We conducted a cross-sectional study including HIV-infected individuals who were being followed up at the Outpatient Clinic of the Care and Therapy Service (SAT), Hospital Sanatório Partenon, State Department of Health of Rio Grande do Sul, Brazil. This clinic and all public health care centers provide medical care, antiretroviral therapy (ART), antihypertensives, and other medications free of charge for $\mathrm{HIV}$-infected patients. We consecutively enrolled female and male patients, aged 18 or older, who were seen between June 2006 and December 2008. Pregnant women, individuals who were unable to provide written consent, or those incarcerated were excluded. Participants who were under the influence of alcohol or drugs at the time of the interview were asked to return for evaluation at another time.

Participants were interviewed on the day of the regular medical appointments. Since they had to consult every month, in order to get antiretroviral medication, they were seen often, which contributed to achieving high participation rate. Information was collected, using standardized questionnaires, for the following characteristics: demographic (age and skin color self-reported, classified as white or nonwhite), socioeconomic (educational attainment, number of school years), and lifestyle characteristics (alcohol consumption, physical activity, and smoking), as well as the use of antiretroviral therapy (ART), and time since diagnosis of HIV infection (in years, classified as $\geq 6$ years, from 3.0 to 5.9 years, and $<3$ years). Data related to HIV infection as CD4 lymphocyte count $\left(\mathrm{mm}^{3} / \mathrm{mL}\right)$, viral load (copies per $\mathrm{mL}$ of blood), and clinical information were confirmed by medical records. Alcohol consumption was investigated using a validated quantity-frequency questionnaire based on the kind of beverage consumed [21], administered by a physician or healthcare professional, containing questions about type, frequency, and amount of alcohol consumed in the last six months. Alcohol consumption was categorized into abstemious drinking, social drinking ( $>0$ and $<15$ grams/day for women and $>0$ and $<30$ grams/day for men), or abusive drinking ( $\geq 15$ grams/day for women and $\geq 30$ grams/day for men) $[21,22,25]$. Binge drinking was characterized by a consumption of five or more drinks on a single occasion [22]. Frequency of consumption was classified as weekly (consumption on some days of the week, but not daily) or monthly (consumption on some days of the month but not every week), regardless of the amount. Physical activity was investigated using the IPAQ (International Physical Activity Questionnaire) [26], which investigates frequency and duration of physical activity. The intensity of exercise was classified as moderate or high versus low physical activity according to the IPAQ protocol [27]. Smoking was defined according to the information provided by the participants, classifying the amount of consumption in at least 100 cigarettes during their lifetimes.

Weight (Kg) and height (m) were measured twice with the participants being barefoot and wearing light clothes, using an anthropometric scale (Filizola, model 31 adult, Indústria Filizola S.A., São Paulo, SP, Brazil). Body mass index (BMI; $\mathrm{kg} / \mathrm{m}^{2}$ ) was calculated as the weight $(\mathrm{kg})$ divided by the square of the height $(\mathrm{m})$ and classified as normal $(<25.0)$, overweight (25-29.9), and obesity ( $\geq 30.0)$. Standardized measurements of blood pressure were obtained in duplicate in two visits, using a validated oscillometric device (OMRON CP-705) [28]. The average of four BP measurements was used to detect hypertension if systolic blood pressure $\geq 140 \mathrm{mmHg}$ or diastolic blood pressure $\geq 90 \mathrm{mmHg}$, or in use of blood pressure-lowering agents [25].

Certified researchers performed the interviews and measured anthropometric parameters and blood pressure. Approximately $5 \%$ of the interviews were repeated for quality control. Data were entered twice into the database of Epinfo, version 2000. The study was approved by the Research Ethics Committee of the Hospital de Clínicas de Porto Alegre, which is accredited by the Office of Human Research Protections. All participants signed an informed consent form.

Sample Size Calculation and Statistical Analysis. Sample size calculation was based on the estimated prevalence of hypertension between white and nonwhite participants with abusive alcohol consumption (30 and 35\%, resp.) and abstemious drinking (18\%), with $80 \%$ of power and a significance level of 0.05 (two-tailed). A sample size of 738 white and 398 nonwhite participants with a 1:5 ratio for exposed and unexposed participants to excessive alcohol consumption would be required to detect a hazard ratio of at least 1.7. The estimates were based on previous studies [22, 29].

Characteristics of the sample were expressed as mean and standard deviation. We used Pearson's chi-square test for the analysis of categorical variables and analysis of variance (continuous variables) to assess the association between these factors and the different outcomes. Confounding factors were controlled using the modified Poisson regression (robust variance estimates) [30] and analysis of covariance. Statistical analyses were performed using the Statistical Package for the Social Sciences (SPSS Inc., Chicago, Illinois, USA), version 18.0. Confounding factors were selected based on the literature $[3,31,32]$ and $P$ values lower than or equal to 0.2 in unadjusted analysis. Age, sex, educational attainment, smoking, physical activity, body mass index, time since HIV infection, and lifetime HAART use were considered confounding factors used in the multivariate models for whites and nonwhites. Partially adjusted models of alcohol consumption with systolic or diastolic blood pressure, including age, sex, and educational attainment, were run in order to better understand the associations and to interpret the risk ratios. A trend for association was determined by $P$ values between 0.05 and 0.1 . 
TABLE 1: Characteristics of HIV-infected individuals according to skin color ( $n(\%)$ or mean \pm SD).

\begin{tabular}{|c|c|c|c|c|}
\hline & Total $(n=1240)$ & Whites $(n=710)$ & Nonwhites $(n=530)$ & $P$ value \\
\hline Male & $628(50.6)$ & $391(55.1)$ & $237(44.7)$ & $<0.001$ \\
\hline Age (years) & $39.1 \pm 10.0$ & $39.3 \pm 10.3$ & $38.9 \pm 9.7$ & 0.5 \\
\hline Educational attainment (years) & $7.5 \pm 4.1$ & $8.3 \pm 4.2$ & $6.4 \pm 3.7$ & $<0.001$ \\
\hline Smoking & $525(42.3)$ & $298(42.0)$ & $227(42.8)$ & 0.4 \\
\hline Physical activity & & & & 0.049 \\
\hline Low & $321(25.9)$ & $199(28.0)$ & $122(23.0)$ & \\
\hline Moderate & $398(32.1)$ & $232(32.7)$ & $166(31.3)$ & \\
\hline High & $521(42.0)$ & $279(39.3)$ & $242(45.7)$ & \\
\hline Alcohol consumption & & & & 0.7 \\
\hline Abstemious & $414(33.4)$ & $233(32.8)$ & $181(34.2)$ & \\
\hline Social drinking & $757(61.0)$ & $440(62.0)$ & $317(59.8)$ & \\
\hline Abusive drinking & $69(5.6)$ & $37(5.2)$ & $32(6.0)$ & \\
\hline Frequency of alcohol consumption & & & & 0.7 \\
\hline Abstemious & $414(33.4)$ & $233(32.8)$ & $181(34.2)$ & \\
\hline Monthly & $440(35.5)$ & $249(35.1)$ & $191(36.0)$ & \\
\hline Weekly & $386(31.1)$ & $228(32.1)$ & $158(29.8)$ & \\
\hline Binge drinking & $211(17.0)$ & $117(55.5)$ & $94(44.5)$ & 0.7 \\
\hline Abstemious & $414(33.4)$ & $233(32.8)$ & $181(34.2)$ & \\
\hline No & $616(49.7)$ & $360(50.7)$ & $255(48.1)$ & \\
\hline Yes & $210(16.9)$ & $117(16.5)$ & $94(17.7)$ & \\
\hline Body mass index $\left(\mathrm{kg} / \mathrm{m}^{2}\right)$ & $24.9 \pm 4.4$ & $24.8 \pm 4.3$ & $25.0 \pm 4.7$ & 0.4 \\
\hline Systolic blood pressure (mmHg) & $121.8 \pm 18.2$ & $121.8 \pm 17.7$ & $121.8 \pm 18.8$ & 0.9 \\
\hline Diastolic blood pressure $(\mathrm{mmHg})$ & $76.6 \pm 11.4$ & $76.0 \pm 10.7$ & $77.3 \pm 12.3$ & 0.06 \\
\hline Hypertension & $241(19.4)$ & $120(16.9)$ & $121(22.8)$ & 0.009 \\
\hline Time since HIV infection (years) & & & & 0.005 \\
\hline$\geq 6.0$ & $404(32.6)$ & $250(35.3)$ & $154(29.1)$ & \\
\hline $3.0-5.9$ & $350(28.2)$ & $176(24.8)$ & $174(32.8)$ & \\
\hline$<3.0$ & $485(39.1)$ & $283(39.9)$ & $202(38.1)$ & \\
\hline HIV/HCV coinfection & $261(22.2)$ & $143(21.2)$ & $118(23.5)$ & 0.3 \\
\hline AIDS diagnosis & $892(72.2)$ & $510(72.0)$ & $382(72.3)$ & 0.9 \\
\hline Lifetime HAART use & $815(65.7)$ & $467(65.8)$ & $348(65.7)$ & 0.9 \\
\hline Lifetime protease inhibitor use & $468(37.7)$ & $277(39.0)$ & $191(36.0)$ & 0.3 \\
\hline $\mathrm{CD} 4\left(\mathrm{cell} / \mathrm{mm}^{3}\right)$ & & & & 0.08 \\
\hline$<350$ & $476(38.8)$ & $258(36.7)$ & $218(41.6)$ & \\
\hline$\geq 350$ & $751(61.2)$ & $445(63.3)$ & $306(58.4)$ & \\
\hline
\end{tabular}

HAART: highly active antiretroviral therapy; HCV: hepatitis C virus; HIV: human immunodeficiency virus; SD: standard deviation.

\section{Results}

Of the 1,295 HIV-infected patients screened, 1,255 were eligible and 1,240 were included. Thus, forty patients had not confirmed eligibility due to age under 18 years, incarceration, or pregnancy; fifteen refused to participate, and two patients were included in a second attempt due to alcohol intoxication at the first visit. Characteristics of the overall sample are presented in Table 1 by skin color. Participants were aged $39.1 \pm 10$, half of them were males, and $57 \%$ had white skin color. Overall, the distribution of most characteristics was similar among whites and nonwhites, but whites had higher education and time since HIV infection, and nonwhites had high physical activity and prevalence of hypertension.
Risk factors for hypertension among whites and nonwhites are shown in Table 2. The unadjusted analysis showed that only age and BMI were positively associated with hypertension for both categories of skin color. White smokers had lower prevalence of hypertension, whereas among nonwhites there was a trend for the association of alcohol abuse with hypertension. There was no association between variables related to HIV and hypertension.

Table 3 shows that association among the different patterns of alcoholic beverages consumption is roughly similar in whites and nonwhites; abusive consumption of alcohol was associated with hypertension in white and nonwhite HIVinfected individuals, independently of a large set of confounding variables. The frequency of alcohol consumption 
TABLE 2: Risk factors for hypertension among HIV-infected individuals by skin color $(n(\%))$.

\begin{tabular}{|c|c|c|c|c|}
\hline & \multicolumn{2}{|c|}{ Whites $(n=710)$} & \multicolumn{2}{|c|}{ Nonwhites $(n=530)$} \\
\hline & Hypertension (\%) & RR (95\% CI) & Hypertension (\%) & $\mathrm{RR}(95 \% \mathrm{CI})$ \\
\hline \multicolumn{5}{|l|}{ Sex } \\
\hline Female & $48(15.0)$ & 1.0 & $65(22.2)$ & 1.0 \\
\hline Male & $72(18.4)$ & $1.2(0.9-1.7)$ & $56(23.6)$ & $1.1(0.8-1.5)$ \\
\hline$P$ value & & 0.2 & & 0.7 \\
\hline \multicolumn{5}{|l|}{ Age (years) } \\
\hline $18-34$ & $20(7.4)$ & 1.0 & $23(11.4)$ & 1.0 \\
\hline $35-49$ & $56(16.9)$ & $2.3(1.4-3.7)$ & $63(24.3)$ & $2.1(1.4-3.3)$ \\
\hline $50-78$ & $44(40.4)$ & $5.4(3.4-8.8)$ & $35(50.7)$ & $4.5(2.8-7.0)$ \\
\hline$P$ value & & $<0.001$ & & $<0.001$ \\
\hline \multicolumn{5}{|c|}{ Educational attainment (years) } \\
\hline$\geq 9$ & $58(17.8)$ & 1.0 & $23(17.8)$ & 1.0 \\
\hline $5-8$ & $38(16.2)$ & $0.9(0.6-1.3)$ & $51(22.2)$ & $1.2(0.8-1.9)$ \\
\hline $0-4$ & $24(16.0)$ & $0.9(0.6-1.4)$ & $47(27.5)$ & $1.5(1.0-2.4)$ \\
\hline$P$ value & & 0.8 & & 0.14 \\
\hline \multicolumn{5}{|l|}{ Smoking } \\
\hline No & $85(20.6)$ & 1.0 & $76(25.1)$ & 1.0 \\
\hline Yes & 35 (11.7) & $0.6(0.4-0.8)$ & $45(19.8)$ & $0.8(0.6-1.1)$ \\
\hline$P$ value & & 0.002 & & 0.16 \\
\hline \multicolumn{5}{|l|}{ Physical activity } \\
\hline High & $39(14.0)$ & 1.0 & $48(19.8)$ & 1.0 \\
\hline Moderate & $44(19.0)$ & $1.4(0.9-2.0)$ & $38(22.9)$ & $1.2(0.8-1.7)$ \\
\hline Low & $37(18.6)$ & $1.3(0.9-2.0)$ & $35(28.7)$ & $1.4(1.0-2.1)$ \\
\hline$P$ value & & 0.3 & & 0.16 \\
\hline \multicolumn{5}{|l|}{ Alcohol consumption } \\
\hline Abstemious & $41(17.6)$ & 1.0 & $41(22.7)$ & 1.0 \\
\hline Social drinking & $70(15.9)$ & $0.9(0.6-1.3)$ & $68(21.5)$ & $0.9(0.7-1.3)$ \\
\hline Abusive drinking & $9(24.3)$ & $1.4(0.7-2.6)$ & $12(37.5)$ & $1.7(1.0-2.8)$ \\
\hline$P$ value & & 0.4 & & 0.08 \\
\hline \multicolumn{5}{|c|}{ Frequency of alcohol consumption } \\
\hline Abstemious & $41(18.0)$ & 1.0 & $41(22.7)$ & 1.0 \\
\hline Monthly & $41(17.6)$ & $0.9(0.6-1.3)$ & $42(26.6)$ & $0.9(0.6-1.3)$ \\
\hline Weekly & $38(15.3)$ & $1.1(0.7-1.5)$ & $79(21.2)$ & $1.2(0.8-1.7)$ \\
\hline$P$ value & & 0.7 & & 0.3 \\
\hline \multicolumn{5}{|l|}{ Binge drinking } \\
\hline Abstemious & $41(17.6)$ & 1.0 & $41(22.7)$ & 1.0 \\
\hline No & $60(16.7)$ & $0.9(0.7-1.4)$ & $60(23.4)$ & 1.0 \\
\hline Yes & $19(16.2)$ & $0.9(0.6-1.5)$ & $20(21.5)$ & $1.0(0.6-1.5)$ \\
\hline$P$ value & & 0.9 & & 0.8 \\
\hline \multicolumn{5}{|c|}{ Body mass index $\left(\mathrm{kg} / \mathrm{m}^{2}\right)$} \\
\hline$<25.0$ & $36(8.7)$ & 1.0 & $45(15.3)$ & 1.0 \\
\hline $25-29.9$ & $58(26.6)$ & $3.1(2.1-4.5)$ & $40(24.7)$ & $1.6(1.1-2.4)$ \\
\hline$\geq 30.0$ & $26(32.9)$ & $3.8(2.4-5.9)$ & $36(49.3)$ & $3.2(2.3-4.6)$ \\
\hline$P$ value & & $<0.001$ & & $<0.001$ \\
\hline \multicolumn{5}{|l|}{ HIV/HCV coinfection } \\
\hline No & $96(18.0)$ & 1.0 & $85(22.1)$ & 1.0 \\
\hline Yes & $22(15.4)$ & $0.9(0.6-1.3)$ & $29(24.6)$ & $1.1(0.8-1.6)$ \\
\hline$P$ value & & 0.5 & & 0.6 \\
\hline
\end{tabular}


TABLE 2: Continued.

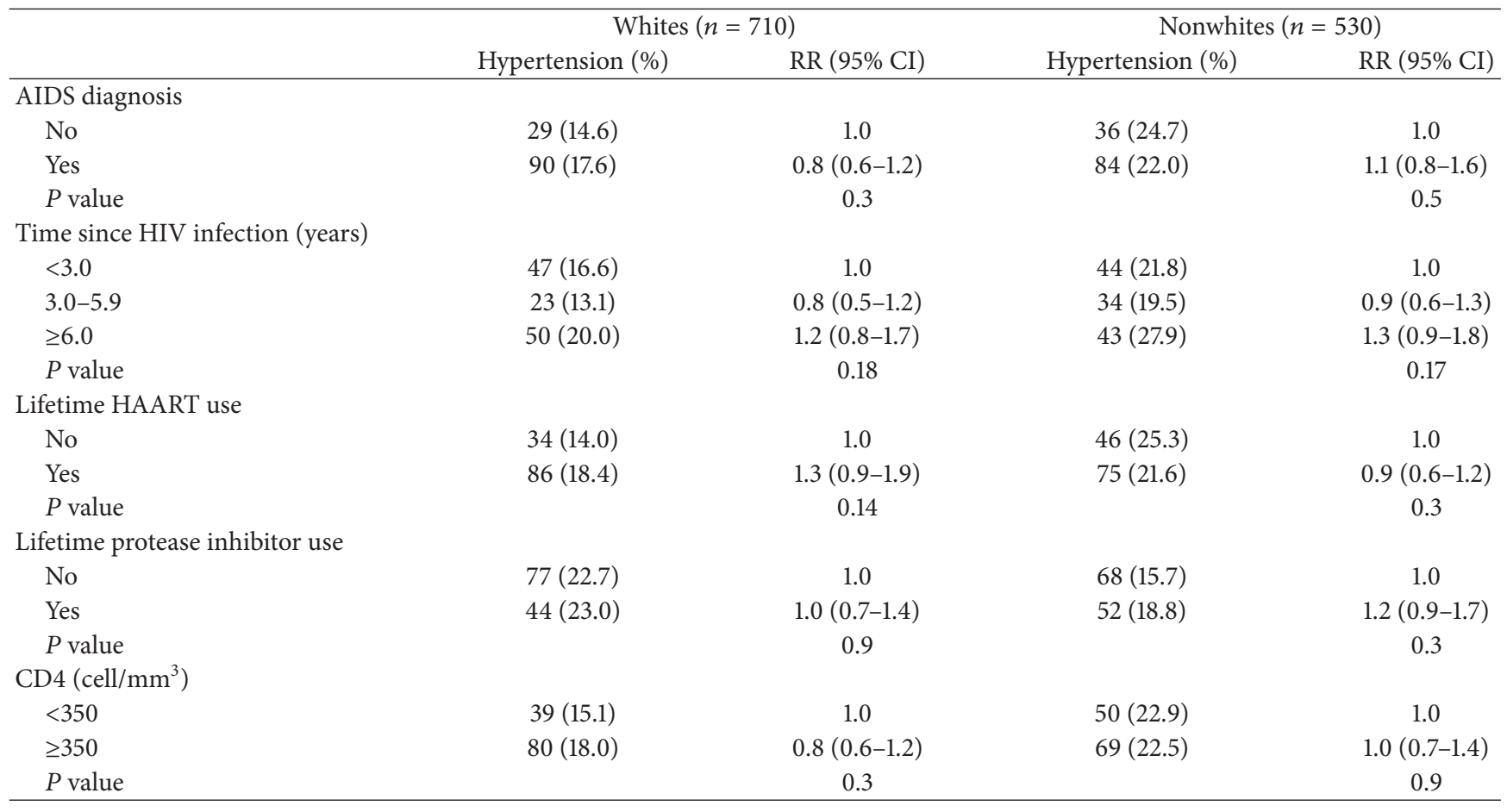

HAART: highly active antiretroviral therapy; HCV: hepatitis C virus; HIV: human immunodeficiency virus; RR: risk ratio.

TABLE 3: Association between alcohol consumption and hypertension according to skin color.

\begin{tabular}{lcc}
\hline & $\begin{array}{c}\text { Whites } \\
\text { RR }(95 \% \mathrm{CI})^{*}\end{array}$ & $\begin{array}{c}\text { Nonwhites } \\
\text { RR }(95 \% \mathrm{CI})^{*}\end{array}$ \\
\hline Alcohol consumption & & \\
$\quad$ Abstemious & 1.0 & 1.0 \\
Social drinking & $1.2(0.8-1.7)$ & $1.1(0.8-1.5)$ \\
Abusive drinking & $1.9(1.1-3.3)$ & $2.4(1.4-4.0)$ \\
$P$ value & 0.09 & 0.004 \\
Frequency of alcohol consumption & & \\
$\quad$ Abstemious & 1.0 & 1.0 \\
Monthly & $1.1(0.7-1.6)$ & $1.0(0.7-1.5)$ \\
$\quad$ Weekly & $1.4(1.0-2.0)$ & $1.3(0.9-1.9)$ \\
$P$ value & 0.2 & 0.18 \\
Binge drinking & \multicolumn{2}{c}{} \\
$\quad$ Abstemious & 1.0 & 1.0 \\
No & $1.2(0.8-1.7)$ & $1.1(0.6-1.8)$ \\
Yes & $1.2(0.8-1.9)$ & $1.2(0.8-1.6)$ \\
$P$ value & 0.6 & 0.7 \\
\hline
\end{tabular}

${ }^{*}$ RR adjusted for age, sex, educational attainment, smoking, physical activity, BMI, time since diagnosis of HIV infection, and use of highly active antiretroviral therapy.

and acute intake of large amounts were not associated with hypertension.

Systolic and diastolic blood pressure was higher exclusively in nonwhite participants who abused alcohol, independently of confounding factors (Table 4). Systolic blood pressure was on average $9.3 \pm 3.2 \mathrm{mmHg}$, and diastolic $6.4 \pm$ $2.1 \mathrm{mmHg}$ greater among abusers. These differences were independent of age, sex, and educational attainment (data not shown) and of full control for confounding factors. Among white participants, there were an association of diastolic blood pressure with weekly consumption of alcoholic beverages in comparison with nondrinkers and a borderline association versus monthly consumers.

\section{Discussion}

In this study, we found that the consumption of large amounts of alcohol was independently associated with hypertension in white and nonwhite HIV-infected individuals. Blood pressure, on the other hand, was higher exclusively in nonwhite abusers of ethanol, demonstrated after adjustment for confounding factors. However, even partially adjusted models showed the presence of negative confounding factors. Among, whites there was an association of blood pressure with the frequency of consumption. Taken together, these findings suggest that among nonwhite participants quantity is more important than the pattern of consumption, while for whites the frequency of drinking is more relevant.

The association between alcohol abuse and hypertension identified in our study is in agreement with findings from other populations [33]. The association of blood pressure with abusive consumption exclusively in nonwhites was similar to the observed one in the ARIC cohort study (Atherosclerosis Risk in Communities) [3] and in a cohort carried out in southern Brazil [22]. It is unlikely that this differential association of alcohol abuse and blood pressure by skin color is due 
TABLE 4: Association of systolic and diastolic blood pressure with alcohol consumption by skin color.

\begin{tabular}{|c|c|c|c|c|c|c|}
\hline Skin color & Alcohol consumption & $\mathrm{BP} \pm \mathrm{SE}(\mathrm{mmHg})$ & $\begin{array}{l}\text { Delta of BP } \pm \text { SE } \\
(\mathrm{mmHg})^{* \dagger}\end{array}$ & $P$ value $^{* \dagger}$ & $\begin{array}{l}\text { Delta of BP } \pm \text { SE } \\
(\mathrm{mmHg})^{* * \dagger}\end{array}$ & $P$ value ${ }^{* * \dagger}$ \\
\hline \multicolumn{7}{|c|}{ Systolic BP $(\mathrm{mmHg})$} \\
\hline \multirow{3}{*}{ Whites } & Abstemious & $120.5 \pm 1.0$ & - & & - & \\
\hline & Social drinking & $122.5 \pm 0.7$ & $2.0 \pm 1.3$ & 0.3 & - & \\
\hline & Abusive drinking & $123.3 \pm 2.5$ & $2.8 \pm 2.8$ & 0.7 & $0.9 \pm 2.7$ & 1.0 \\
\hline \multirow{3}{*}{ Nonwhites } & Abstemious & $120.8 \pm 1.3$ & - & & - & \\
\hline & Social drinking & $121.6 \pm 0.9$ & $0.8 \pm 1.6$ & 0.9 & - & \\
\hline & Abusive drinking & $130.9 \pm 3.0$ & $10.1 \pm 3.3$ & 0.007 & $9.3 \pm 3.2$ & 0.01 \\
\hline \multicolumn{7}{|c|}{ Diastolic BP ( $\mathrm{mmHg})$} \\
\hline \multirow{3}{*}{ Whites } & Abstemious & $74.9 \pm 0.6$ & - & & - & \\
\hline & Social drinking & $76.6 \pm 0.5$ & $1.7 \pm 0.8$ & 0.1 & - & \\
\hline & Abusive drinking & $77.4 \pm 1.6$ & $2.6 \pm 1.7$ & 0.4 & $0.9 \pm 1.7$ & 0.9 \\
\hline \multirow{4}{*}{ Nonwhites } & Abstemious & $76.6 \pm 0.9$ & - & & - & \\
\hline & Social drinking & $77.1 \pm 0.6$ & $0.5 \pm 1.1$ & 0.9 & - & \\
\hline & Abusive drinking & $83.4 \pm 2.0$ & $6.9 \pm 2.2$ & 0.006 & $6.4 \pm 2.1$ & 0.008 \\
\hline & $\begin{array}{c}\text { Frequency of alcohol } \\
\text { consumption }\end{array}$ & & & & & \\
\hline \multicolumn{7}{|c|}{ Systolic BP $(\mathrm{mmHg})$} \\
\hline \multirow{3}{*}{ Whites } & Abstemious & $120.5 \pm 1.0$ & - & & & \\
\hline & Monthly & $121.6 \pm 1.0$ & $1.1 \pm 1.4$ & 0.9 & - & \\
\hline & Weekly & $123.5 \pm 1.0$ & $3.0 \pm 1.5$ & 0.4 & $2.3 \pm 1.8$ & 0.5 \\
\hline \multirow{3}{*}{ Nonwhites } & Abstemious & $120.8 \pm 1.3$ & - & & & \\
\hline & Monthly & $121.3 \pm 1.2$ & $0.5 \pm 1.8$ & 0.8 & - & \\
\hline & Weekly & $123.6 \pm 1.4$ & $2.8 \pm 2.0$ & 0.12 & $1.9 \pm 1.4$ & 0.5 \\
\hline \multicolumn{7}{|c|}{ Diastolic BP (mmHg) } \\
\hline \multirow{3}{*}{ Whites } & Abstemious & $74.9 \pm 0.6$ & & & & \\
\hline & Monthly & $75.7 \pm 0.6$ & $0.8 \pm 0.9$ & 0.8 & & \\
\hline & Weekly & $77.6 \pm 0.6$ & $2.8 \pm 0.9$ & 0.008 & $2.0 \pm 0.9$ & 0.079 \\
\hline \multirow{3}{*}{ Nonwhites } & Abstemious & $76.7 \pm 0.9$ & & & & \\
\hline & Monthly & $77.5 \pm 0.8$ & $0.8 \pm 1.2$ & 0.9 & & \\
\hline & Weekly & $77.7 \pm 0.9$ & $1.0 \pm 1.3$ & 0.8 & $0.2 \pm 1.2$ & 0.9 \\
\hline
\end{tabular}

SE: standard error; ${ }^{*}$ delta in relation to abstemious drinking; ${ }^{* *}$ delta in relation to social drinking or monthly consumption; ${ }^{\dagger}$ analyses of covariance adjusted for age, sex, educational attainment, smoking, physical activity, body mass index, time since HIV infection, and lifetime HAART use.

to race or ethnicity, but probably relies on other behavioral characteristics of nonwhite individuals [34]. Anyway, blood pressure was higher exclusively in nonwhite abusers, suggesting that these individuals are at higher risk of the harmful effects of ethanol.

Our study adds a piece of mind in the investigation of the influence of HIV-related characteristics and higher incidence of cardiovascular disease. It has been suggested that the use of HAART may be associated with increasing blood pressure $[9,10,35,36]$. In some studies, longer time of HAART was associated with hypertension $[13,37]$. These associations were not identified in our study, since the use of antiretrovirals, time of HIV infection, AIDS, and CD4 count were not associated with hypertension.

Some limitations of our study deserve to be mentioned. The cross-sectional design does not allow inferring causality. Data on alcohol consumption were obtained from a standardized questionnaire containing detailed information, but it relies on memory, and because it was applied in the context of medical care, this might have led individuals to underreport consumption. Another aspect to be considered is the fact that blood pressure measurements were performed at the medical consultation, and therefore the possibility of a white coat effect cannot be discarded. Even underreporting alcohol consumption or the white coat effect, the association of alcohol abuse with hypertension has been confirmed by ambulatory monitoring of blood pressure [38]. The prospective planning, together with the extensive and detailed measurement of AIDS-related and nonrelated characteristics and adequate statistical power, is a strength of our investigation.

\section{Conclusions}

In conclusion, alcohol abuse is associated with increased risk of hypertension in white and nonwhite HIV-infected individuals. Blood pressure is higher only in nonwhite individuals 
who abuse alcoholic beverages and in whites who drink weekly. The association of ethanol consumption with blood pressure is not explained by AIDS-related conditions.

\section{Conflict of Interests}

The authors declare that they have no conflict of interests.

\section{Acknowledgments}

The financial support was provided by the National Council for Scientific and Technological Development (CNPq), Ministry of Health/Secretariat of Health Surveillance/National STD and AIDS Program (MOH/SHS/NAP), Research funding from Hospital de Clínicas de Porto Alegre (FIPE-HCPA), and National Institute for Science and Technology for Health Technology Assessment (IATS/CNPq), Porto Alegre, RS, Brazil. The sponsors did not take part in the design or conduct of the study, including data collection, management, analysis, and interpretation of the data, and preparation, review, or approval of the paper.

\section{References}

[1] P. M. Kearney, M. Whelton, K. Reynolds, P. Muntner, P. K. Whelton, and J. He, "Global burden of hypertension: analysis of worldwide data," The Lancet, vol. 365, no. 9455, pp. 217-223, 2005.

[2] R. V. Picon, F. D. Fuchs, L. B. Moreira, G. Riegel, and S.C. Fuchs, "Trends in prevalence of hypertension in Brazil: a systematic review with meta-analysis," PloS ONE, vol. 7, no. 10, Article ID e48255, 2012.

[3] F. D. Fuchs, L. E. Chambless, P. K. Whelton, F. J. Nieto, and G. Heiss, "Alcohol consumption and the incidence of hypertension. The Atherosclerosis Risk in Communities Study," Hypertension, vol. 37, no. 5, pp. 1242-1250, 2001.

[4] C. C. Gravlee, W. W. Dressier, and H. Russell Bernard, "Skin color, social classification, and blood pressure in Southeastern Puerto Rico," American Journal of Public Health, vol. 95, no. 12, pp. 2191-2197, 2005.

[5] S.-Y. Fu, W.-M. Li, Y.-J. Zhao et al., "Prevalence of hypertension and risk factors in Heilongjiang province in 2007," Chinese Medical Journal, vol. 123, no. 6, pp. 752-755, 2010.

[6] J. M. Núñez-Córdoba, M. A. Martínez-González, M. BesRastrollo, E. Toledo, J. J. Beunza, and Á. Alonso, "Alcohol Consumption and the Incidence of Hypertension in a Mediterranean Cohort. The SUN Study," Revista Espanola de Cardiologia, vol. 62, no. 6, pp. 633-641, 2009.

[7] S. MacMahon, "Alcohol consumption and hypertension," Hypertension, vol. 9, no. 2, pp. 111-121, 1987.

[8] M. S. Freiberg and K. L. Kraemer, "Focus on the heart: alcohol consumption, HIV infection, and cardiovascular disease," Alcohol Research and Health, vol. 33, no. 3, pp. 237-246, 2010.

[9] M. Baekken, I. Os, L. Sandvik, and O. Oektedalen, "Hypertension in an urban HIV-positive population compared with the general population: influence of combination antiretroviral therapy," Journal of Hypertension, vol. 26, no. 11, pp. 2126-2133, 2008.

[10] C. Jericó, H. Knobel, M. Montero et al., "Hypertension in HIVinfected patients: prevalence and related factors," American Journal of Hypertension, vol. 18, no. 11, pp. 1396-1401, 2005.
[11] N. Friis-Møller, R. Weber, P. Reiss et al., "Cardiovascular disease risk factors in HIV patients-association with antiretroviral therapy. Results from the DAD study," AIDS, vol. 17, no. 8, pp. 1179-1193, 2003.

[12] S. Medina-Torne, A. Ganesan, I. Barahona, and N. F. CrumCianflone, "Hypertension is common among HIV-infected persons, but not associated with HAART," Journal of the International Association of Physicians in AIDS Care, vol. 11, no. 1, pp. 20-25, 2012.

[13] I. W. Manner, M. Baekken, O. Oektedalen, L. Sandvik, and I. Os, "Effect of HIV duration on ambulatory blood pressure in HIV-infected individuals with high office blood pressure," Blood Pressure, vol. 19, no. 3, pp. 188-195, 2010.

[14] M. Bonacini, "Alcohol use among patients with HIV infection," Annals of Hepatology, vol. 10, no. 4, pp. 502-507, 2011.

[15] M. S. Freiberg, K. A. McGinnis, K. Kraemer et al., "The association between alcohol consumption and prevalent cardiovascular diseases among HIV-infected and HIV-uninfected men," Journal of Acquired Immune Deficiency Syndromes, vol. 53, no. 2, pp. 247-253, 2010.

[16] S. J. Phillips, K. A. Freedberg, E. T. Traphagen, N. J. Horton, and J. H. Samet, "Screening for alcohol problems in HIV-infected primary care patients," Journal of General Internal Medicine, vol. 16, no. 1, p. S165, 2001.

[17] J. H. Samet, S. J. Phillips, N. J. Horton, E. T. Traphagen, and K. A. Freedberg, "Detecting alcohol problems in HIV-infected patients: use of the CAGE questionnaire," AIDS Research and Human Retroviruses, vol. 20, no. 2, pp. 151-155, 2004.

[18] J. Conigliaro, A. J. Gordon, K. A. McGinnis, L. Rabeneck, and A. C. Justice, "How harmful is hazardous alcohol use and abuse in HIV infection: do health care providers know who is at risk?" Journal of Acquired Immune Deficiency Syndromes, vol. 33, no. 4, pp. 521-525, 2003.

[19] B. F. Grant, D. A. Dawson, F. S. Stinson, S. P. Chou, M. C. Dufour, and R. P. Pickering, "The 12-month prevalence and trends in DSM-IV alcohol abuse and dependence: United States, 19911992 and 2001-2002," Drug and Alcohol Dependence, vol. 74, no. 3, pp. 223-234, 2004.

[20] N. Rehn, R. Room, and G. Edwards, Alcohol in the European Region-Consumption, Harm and Policies, Regional Office for Europe, World Health Organization, 2001.

[21] L. B. Moreira, F. D. Fuchs, R. S. Moraes, M. Bredemeier, and B. B. Duncan, "Alcohol intake and blood pressure: the importance of time elapsed since last drink," Journal of Hypertension, vol. 16, no. 2, pp. 175-180, 1998.

[22] A. A. Steffens, L. B. Moreira, S. C. Fuchs, M. Wiehe, M. Gus, and F. D. Fuchs, "Incidence of hypertension by alcohol consumption: is it modified by race?" Journal of Hypertension, vol. 24, no. 8, pp. 1489-1492, 2006.

[23] D. S. Minor, M. R. Wofford, and D. W. Jones, "Racial and ethnic differences in hypertension," Current Atherosclerosis Reports, vol. 10, no. 2, pp. 121-127, 2008.

[24] M. S. Mujahid, A. V. Diez Roux, R. C. Cooper, S. Shea, and D. R. Williams, "Neighborhood stressors and race/ethnic differences in hypertension prevalence (the Multi-Ethnic Study of atherosclerosis)," American Journal of Hypertension, vol. 24, no. 2, pp. 187-193, 2011.

[25] A. V. Chobanian, G. L. Bakris, H. R. Black et al., "The Seventh Report of the Joint National Committee on prevention, detection, evaluation, and treatment of high blood pressure," Journal of the American Medical Association, vol. 289, no. 19, pp. 25602572, 2003. 
[26] C. L. Craig, A. L. Marshall, M. Sjöström et al., "International physical activity questionnaire: 12 -country reliability and validity," Medicine and Science in Sports and Exercise, vol. 35, no. 8, pp. 1381-1395, 2003.

[27] https://sites.google.com/site/theipaq/scoring-protocol.

[28] E. O'Brien, F. Mee, N. Atkins, and M. Thomas, "Evaluation of three devices for self-measurement of blood pressure according to the revised British Hypertension Society Protocol. The Omron HEM-705CP, Philips HP5332, and Nissei DS-175," Blood Pressure Monitoring, vol. 1, no. 1, pp. 55-61, 1996.

[29] P. R. Alencastro, S. C. Fuchs, F. H. Wolff, M. L. Ikeda, A. B. M. Brandão, and N. T. Barcellos, "Independent predictors of metabolic syndrome in HIV-infected patients," AIDS Patient Care and STDs, vol. 25, no. 11, pp. 627-634, 2011.

[30] A. J. D. Barros and V. N. Hirakata, "Alternatives for logistic regression in cross-sectional studies: an empirical comparison of models that directly estimate the prevalence ratio," $B M C$ Medical Research Methodology, vol. 3, article 1, 2003.

[31] N. T. Barcellos, S. C. Fuchs, and F. D. Fuchs, "Prevalence of and risk factors for HIV infection in individuals testing for HIV at counseling centers in Brazil," Sexually Transmitted Diseases, vol. 30, no. 2, pp. 166-173, 2003.

[32] C. G. Victora, S. R. Huttly, S. C. Fuchs, and M. T. A. Olinto, "The role of conceptual frameworks in epidemiological analysis: a hierarchical approach," International Journal of Epidemiology, vol. 26, no. 1, pp. 224-227, 1997.

[33] L. J. Beilin, I. B. Puddey, and V. Burke, "Alcohol and hypertension-kill or cure?" Journal of Human Hypertension, vol. 10, no. 2, supplement, pp. S1-S5, 1996.

[34] A. L. Klatsky, "Alcohol and cardiovascular health," Physiology and Behavior, vol. 100, no. 1, pp. 76-81, 2010.

[35] R. Thiébaut, W. M. El-Sadr, N. Friis-Møller et al., "Predictors of hypertension and changes of blood pressure in HIV-infected patients," Antiviral Therapy, vol. 10, no. 7, pp. 811-823, 2005.

[36] D. C. Chow, S. A. Souza, R. Chen et al., "Elevated blood pressure in HIV-infected individuals receiving highly active antiretroviral therapy," HIV Clinical Trials, vol. 4, no. 6, pp. 411-416, 2003.

[37] E. C. Seaberg, A. Muñoz, M. Lu et al., "Association between highly active antiretroviral therapy and hypertension in a large cohort of men followed from 1984 to 2003," AIDS, vol. 19, no. 9 , pp. 953-960, 2005.

[38] J. L. Abramson, C. Lewis, and N. V. Murrah, "Relationship of self-reported alcohol consumption to ambulatory blood pressure in a sample of healthy adults," American Journal of Hypertension, vol. 23, no. 9, pp. 994-999, 2010. 


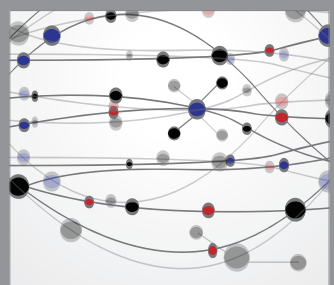

The Scientific World Journal
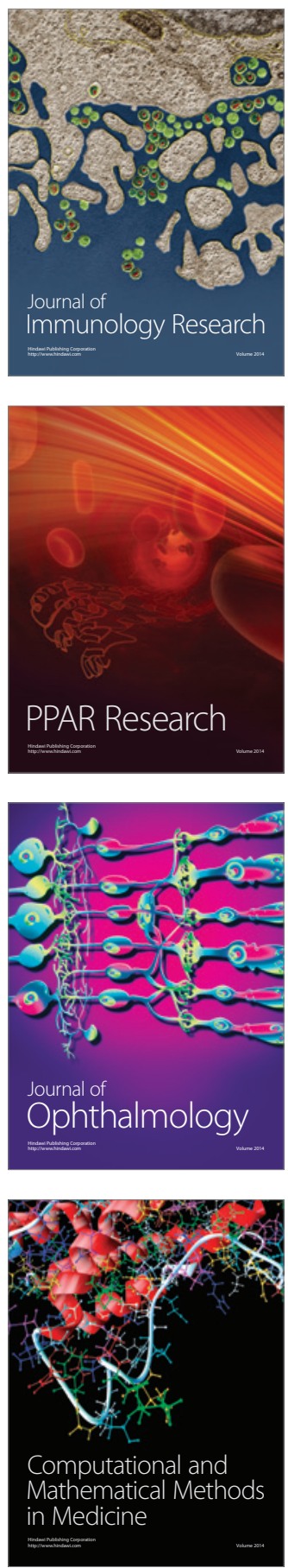

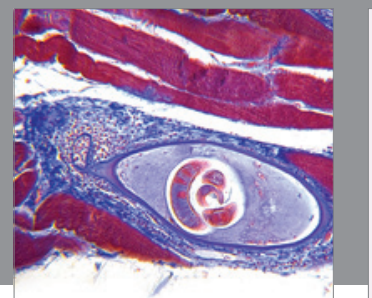

Gastroenterology

Research and Practice
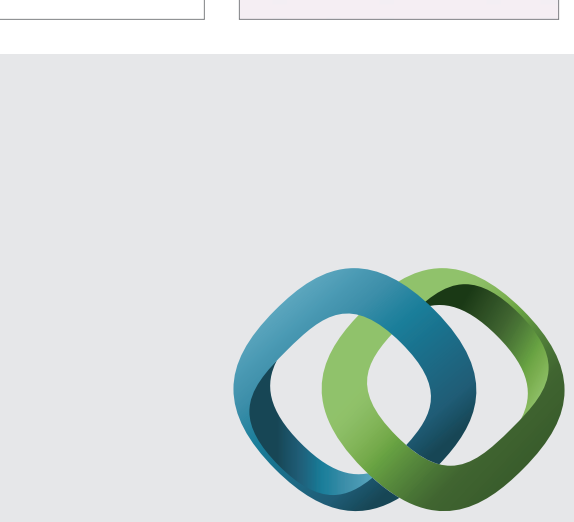

\section{Hindawi}

Submit your manuscripts at

http://www.hindawi.com
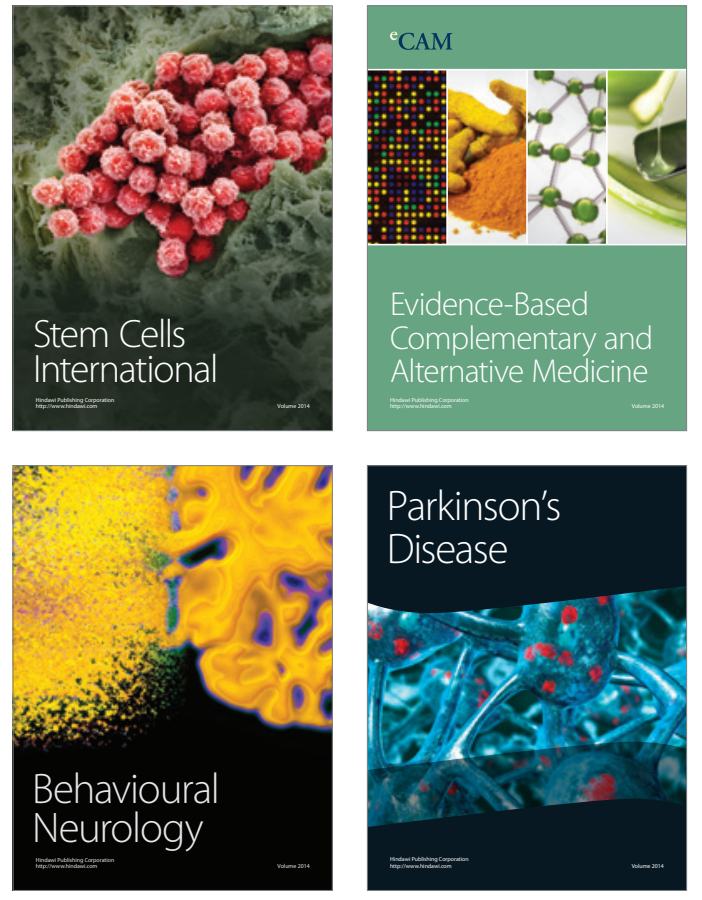
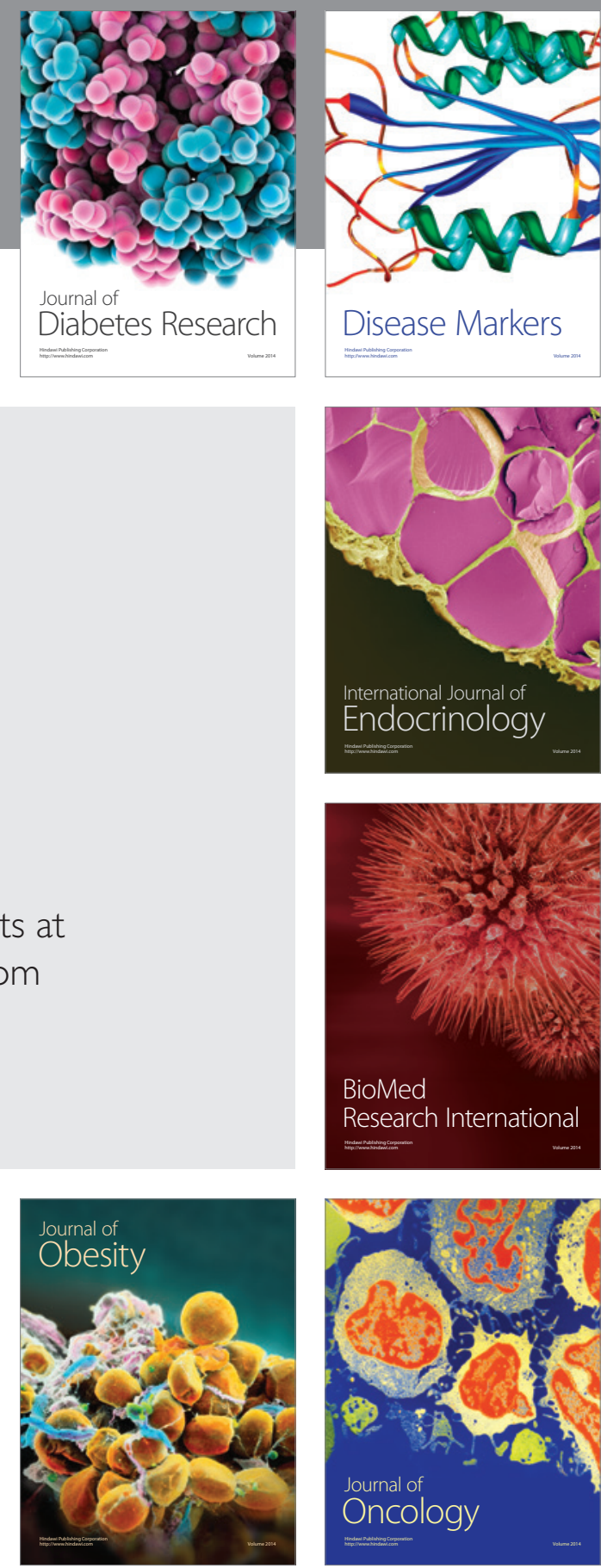

Disease Markers
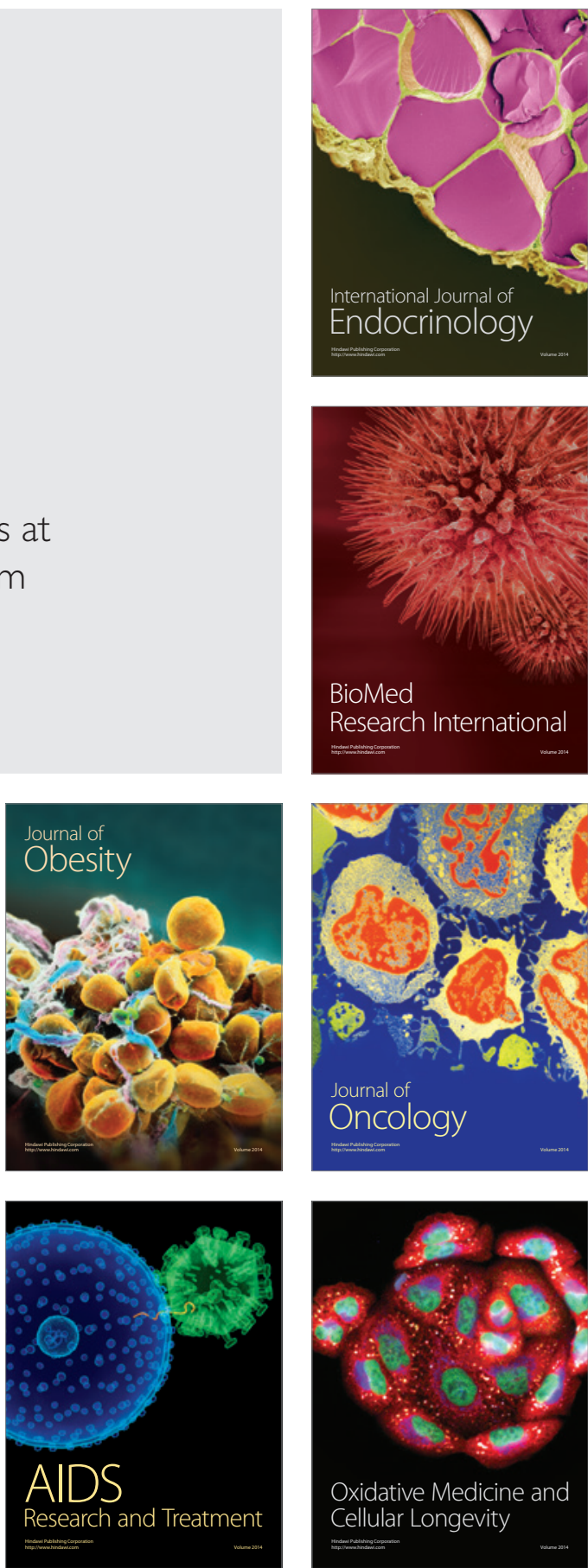